\title{
FORMULASI KRIM ANTIOKSIDAN EKSTRAK DAUN KAPAS (Gossypium sp.)
}

\section{ANTIOXIDANT CREAM FORMULATION OF Gossypium sp. LEAF EXTRACT}

\author{
Hasniar $^{1^{*}}$, Yusriadi ${ }^{1}$, Akhmad Khumaidi ${ }^{1}$ \\ ${ }^{1}$ Jurusan Farmasi, Fakultas MIPA, Universitas Tadulako, Palu, Indonesia \\ Received 25 Desember 2015, Accepted 30 Januari 2015
}

\begin{abstract}
ABSTRAK
Daun kapas (Gossypium sp.) merupakan salah satu tanaman yang mengandung flavonoid yang dapat berfungsi sebagai antioksidan.Penelitian ini bertujuan untuk melihat pengaruh kombinasi asam stearat dan trietanolamin yang berfungsi sebagai emulgator pada krim serta mengetahui aktivitas antioksidan krim ekstrak daun kapas. Krim diformulasi dengan variasi emulgator asam stearat dan trietanolamin yaitu F1 (8\%: $2 \%)$, F2 (12\%: 3\%), F3 (16\%: 4\%). Pengujian dilakukan pada hari ke-1 dan hari ke-28. Evaluasi sediaan mencakup uji organoleptis, homogenitas, viskositas, $\mathrm{pH}$, dan tipe krim. Hasil penelitian menunjukkan bahwa variasi konsentrasi emulgator memenuhi mutu sediaan dengan beberapa parameter yakni organoleptis, homogenitas, tipe krim dan viskositas. $\mathrm{pH}$ krim tidak memenuhi syarat yang ditentukan yakni 4,5-6, namun masih berada dalam kisaran $\mathrm{pH}$ netral $(\mathrm{pH} \pm 7$ ). Data yang diperoleh dianalisis dengan uji $t$-student dan uji ANOVA untuk mengetahui mutu sediaan krim. Aktivitas antioksidan krim mempunyai daya peredaman yang besar pada hari ke-1 yaitu nilai persen peredaman DPPH untuk F1, F2 dan F3 berturut-turut sebesar 80,73\%, 83,05\% dan $83,51 \%$ dan setelah penyimpanan pada hari ke-28 nilai persen peredaman DPPH untuk F1, F2, dan F3 berturutturut sebesar $80,43 \%, 82,49 \%$ dan $79,02 \%$. Krim yang memenuhi stabilitas mutu sediaan krim yaitu krim $\mathrm{F} 1$ dengan menggunakan emulgator trietanolamin dan asam stearat dengan konsentrasi $8 \%: 2 \%$.
\end{abstract}

Kata kunci : Ekstrak daun kapas, antioksidan, emulgator.

\begin{abstract}
Gossypiumsp. leaf is one of the plants that contain flavonoids that can act as antioxidants. This study aims to look at the effect of combination of the stearic acid and triethanolamine which function as emulsifier in creams and determine antioxidant activity of cream Gossypium sp. leaf extract. Cream is formulated with a variety of stearic acid and triethanolamine emulsifier that F1 (8\%: 2\%), F2 (12\%: 3\%), F3 (16\%: 4\%). Tests carried out at the first day and the $28^{\text {th }}$ days. Evaluation preparations include organoleptic test, homogeneity, viscosity, $\mathrm{pH}$, and type of the cream. The results showed that the variation of concentration of emulsifier that fill quality preparations with some parameters such as organoleptic, homogeneity, the type ofcream and viscosity. $\mathrm{pH}$ of cream does not qualify are $4.5-6$, but still in the neutral $\mathrm{pH}$ range $(\mathrm{pH} \pm 7)$. Antioxidant activity of the cream has alarge reduce power at the first day DPPH reduce percent value for F1,F2, and F3 are 80,73\%, 83,05\% and $83,51 \%$ respectively, while after the storage at the $28^{\text {th }}$ days DPPH reduce percent value for F1, F2, and F3 are $80,43 \%, 82,49 \%$ and $79,02 \%$ respectively. Preparation creams that fill physical quality cream is $\mathrm{F} 1$ by using emulsifier triethanolamine and stearic acid with a concentration of $8 \%: 2 \%$.
\end{abstract}

Keywords : Gossypium sp. leaf extract, antioxidant, emulsifier

*Coresponding author : Hasniar, Hasniar_hs@yahoo.co.id 


\section{PENDAHULUAN}

Radikal bebas merupakan salah satu bentuk senyawa oksigen reaktif, yang secara umum diketahui sebagai senyawa yang memiliki elektron yang tidak berpasangan. Adanya elektron yang tidak berpasangan menyebabkan senyawa tersebut sangat reaktif mencari pasangan, dengan cara menyerang dan mengikat elektron molekul yang berada di sekitarnya. Dampak reaktivitas senyawa radikal bebas bermacam-macam, mulai dari kerusakan sel atau jaringan, penyakit autoimun, penyakit degeneratif hingga kanker (Winarsi, 2007). Langkah yang tepat untuk menghadapi radikal bebas adalah dengan mengurangi paparannya atau mengoptimalkan pertahanan tubuh melalui aktivitas antioksidan (Maulida dan Zulkarnaen, 2010).

Salah satu tanaman yang mengandung senyawa antioksidan adalah daun kapas (Sutikno, 2000). Daun kapas mengandung tanin, flavonoid, saponin, dan steroid. Berdasarkan hasil penelitian Kumar et al (2011) yang menyatakan bahwa daun kapas mempunyai $\mathrm{IC}_{50}$ sebesar $44,69 \mu \mathrm{g} / \mathrm{mL}$, dapat dijadikan sumber antioksidan dan dapat mencegah penyakit yang disebabkan radikal bebas.

Untuk mengatasi penuaan, kerusakan jaringan pada kulit, serta untuk melindungi dan untuk perawatan kulitbiasanya digunakan sediaan dalam bentuk topikal seperti krim antioksidan (Kosasih dkk, 2006).

Krim merupakan sediaan setengah padat, berupa emulsi yang mengandung bahan dasar yang sesuai dan mengandung air tidak kurang dari $60 \%$. Krim ada dua tipe, yaitu krim tipe minyak dalam air (M/A) dan tipe air dalam minyak (A/M). Krim yang mudah dicuci dengan air adalah tipe krim (M/A) yang ditujukan untuk penggunaan kosmetik (Syamsuni, 2006).

Emulgator adalah surfaktan yang mengurangi tegangan antarmuka antara minyak dan air, mengelilingi tetesan-tetesan terdispersi dengan lapisan yang kuat sehingga mencegah koalesensi dan pemecahan fase terdispersi. Kestabilan emulsi terutama dipengaruhi oleh variasi dan jumlah emulgator (Anief, 2008). Sifat fisik dan stabilitas sediaan krim akan menentukan keefektifan sediaan saat diaplikasikan pada kulit.
Salah satu bahan yang biasa digunakan sebagai emulgator dalam sediaan krim adalah asam stearat dan trietanolamin. Asam stearat digunakan dalam krim yang mudah dicuci dengan air, sebagai zat pengemulsi untuk memperoleh konsistensi krim tertentu serta untuk memperoleh efek yang tidak menyilaukan pada kulit. Jika asam stearat digunakan sebagai pengemulsi, maka umumnya kalium hidroksida atau trietanolamin ditambahkan secukupnya agar bereaksi dengan $8 \%$ sampai $20 \%$ asam stearat (Lachman, 2008).

Oleh karena itu dalam penelitian ini, ekstrak daun kapas diformulasi dalam bentuk sediaan setengah padat yaitu krim dengan perbandingan emulgator asam stearat dan trietanolamin yang bertujuan untuk mengetahui formula krim yang memiliki kestabilan yang baik yang memenuhi parameter mutu sediaan dengan perbandingan konsentrasi emulgator asam stearat dan trietanolamin serta mengetahui aktivitas antioksidan krim ekstrak daun kapas.

\section{METODE PENELITIAN Bahan}

Daun kapas (Gossypium sp.), DPPH $\left(\right.$ Sigma Aldrich $\left.{ }^{\circledR}\right)$, etanol absolut $\left(\right.$ Merck $\left.^{\circledR}\right)$, asam stearat, setil alkohol, parafin cair, gliserin, trietanolamin, metil paraben, propil paraben, akuades, vitamin $\mathrm{C}$ murni, etanol teknis 96\%, minyak mawar, asam klorida $(\mathrm{HCl})$, Serbuk $\mathrm{Mg}$, besi III clorida $\left(\mathrm{FeCl}_{3}\right)$, asam sulfat $\left(\mathrm{H}_{2} \mathrm{SO}_{4}\right)$, asam asetat $\left(\mathrm{CH}_{3} \mathrm{COOH}\right)$, Eter, pereaksi Bouchardat, pereaksi Dragendorff.

\section{Metode}

\section{Pembuatan Ekstrak}

Serbuk kering daun kapas di ekstraksi secara maserasi menggunakan pelarut etanol 96\%, disimpan selama $3 \times 24$ jam, kemudian disaring. Ekstrak cair yang diperoleh diuapkan dengan menggunakan rotavapor sampai diperoleh ekstrak kental.

\section{Pengujian Aktivitas Antioksidan Dengan Metode DPPH}

Larutan Baku DPPH (0,5 mM) dibuat dengan melarutkan 9,812 mg DPPH dengan etanol absolut hingga 50,0 mL. Kemudian pengujian serapan blanko dilakukan dengan cara memipet $5 \mathrm{~mL}$ dari larutan baku DPPH dan dicukupkan volumenya hingga $25,0 \mathrm{~mL}$ 
(200 ppm) dengan etanol absolut dalam labu tentukur dan diukur absorbansinya dengan spektrofotometer UV-VIS pada panjang gelombang $517 \mathrm{~nm}$.

Untuk pembuatan larutan vitamin $\mathrm{C}$ dan ekstrak daun kapas yang akan diuji aktivitas antioksidannya yaitu dengan melarutkan 25 $\mathrm{mg}$ vitamin Cdalam air bebas $\mathrm{CO}_{2}$ lalu dihomogenkan dan dicukupkan volumenya hingga 25,0 mL (1000 ppm). Sedangkan untuk ekstrak daun kapas dibuat dengan melarutkan 25 mgekstrak daun kapas dengan etanol absolut, dan dicukupkan volumenya dengan etanol absolut hingga 25,0 mL (1000 ppm). Masing-masing larutan tersebut dipipet $3 \mathrm{~mL}$, ditambahkan $5 \mathrm{ml}$ DPPH blanko lalu dicukupkan volumenya sampai $25,0 \mathrm{~mL}$ (120 ppm) dengan etanol absolutlarutan ini kemudian dihomogenkan dan dibiarkan selama 30 menit, dan diukur absorbansinya dengan spektrofotometer UV-VIS pada panjang gelombang $517 \mathrm{~nm}$ (Sinaga, 2009).

Aktivitas antioksidan dinyatakan dengan persen peredaman DPPH. Besarnya daya antioksidan dihitung dengan rumus :

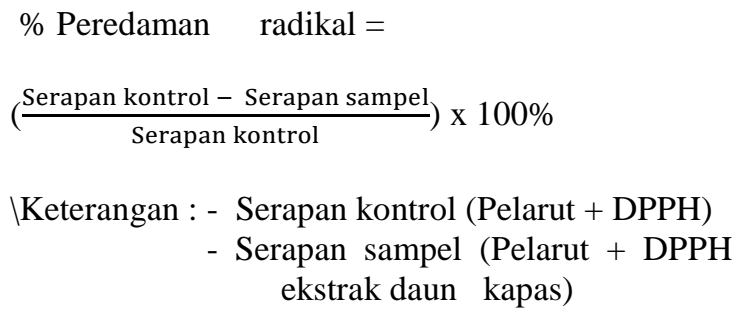

Formula Krim Antioksidan

Tabel 1. Komposisi formula krim antioksidan ekstrak daun kapas

\begin{tabular}{lccc}
\hline \multirow{2}{*}{ BAHAN } & \multicolumn{3}{c}{ Konsentrasi (\%) } \\
\cline { 2 - 4 } & Formula & Formula & Formula \\
\hline Ekstrak daun & 3 & 3 & 3 \\
kapas & 8 & 12 & 16 \\
Asam Stearat & 2 & 3 & 4 \\
Trietanolamin & 2 & 2 & 2 \\
Setil alkohol & 2 & 2 & 2 \\
Parafin cair & 0,02 & 0,02 & 0,02 \\
Propil paraben & 0,18 & 0,18 & 0,18 \\
Metil paraben & 10 & 10 & 10 \\
Gliserin & 0,5 & 0,5 & 0,5 \\
Minyak & & & \\
mawar & ad 100 & ad 100 & ad 100 \\
Akuades & & & \\
\hline
\end{tabular}

\section{Pembuatan Krim}

Krim dibuat dengan cara meleburkan berturut-turut fase minyak asam stearat, setil alkohol, propil paraben, parafin cair di atas penangas air pada suhu $50^{\circ} \mathrm{C}$. Pada wadah lain,membuat fase air dengan cara melarutkan metil paraben dan trietanolamin dalam aquadest dan dipanaskan hingga suhu $70^{\circ} \mathrm{C}$. Ekstrak daun kapas dimasukkan ke dalam mortir dan dilarutkan dengan gliserin, kemudian ditambahkan fase air sedikit demi sedikit digerus sampai homogen, setelah itu ditambahkan fase minyak sedikit demi sedikit lalu digerus sampai homogen, selanjutnya ditambahkan minyak mawar secukupnya, setelah itu dihomogenkan. Kemudian krim dimasukkan ke dalam wadah.

\section{Kontrol Kualitas krim}

Evaluasi sediaan krim yang dilakukan meliputi pengujian mutu fisik krim yaitu : organoleptik, homogenitas, viskositas, $\mathrm{pH}$, tipe krim dan evaluasi stabilitas fisik pada hari ke1 dan hari ke-28 yang di simpanpadasuhukamar. Serta pengujian aktivitas antioksidan sediaan krim ekstrak daun kapas pada hari ke-1 dan hari ke-28.

\section{Pengujian aktivitas antioksidan krim dengan metode DPPH}

Pengujian aktivitas antioksidan sediaan krim yaitu dengan cara menimbang 0,1 gram sediaan lalu dilarutkan dengan etanol absolut, dan dicukupkanvolumenya dengan etanol absolut hingga 100,0 mL. Larutan tersebut dipipet $3 \mathrm{~mL}$, ditambahkan $5 \mathrm{~mL}$ DPPH blanko dan dicukupkanvolumenya hingga 25,0 mL (120 ppm) dengan etanol absolut dandidiamkan selama 30 menit lalu diukur absorbansinya dengan spektrofotometer pada panjang gelombang $517 \mathrm{~nm}$.

\section{HASIL DAN PEMBAHASAN \\ Hasil}

Simplisia daun kapas diekstraksi dengan metode maserasi menggunakan pelarut etanol. Hasil ekstrak kental daun kapas yang diperoleh sebanyak 64,92 gram dengan rendemen $11,57 \%$.

Hasil uji aktivitas antioksidan menunjukkan bahwa persen peredaman ekstrak daun kapas sebesar 92,90\% dan persen peredaman vitamin $\mathrm{C}$ yang digunakan sebagai pembanding sebesar $98,93 \%$. 
Tabel 2. Hasil pemeriksaan sediaan

\begin{tabular}{|c|c|c|c|c|c|c|}
\hline \multirow{2}{*}{$\begin{array}{c}\text { Pemeriksaa } \\
n\end{array}$} & \multicolumn{6}{|c|}{ Sediaan krim } \\
\hline & $\mathrm{F} 1 \mathrm{H}_{1}$ & $\mathrm{~F} 1 \mathrm{H}_{28}$ & $\mathrm{~F} 2 \mathrm{H}_{1}$ & $\mathrm{~F} 2 \mathrm{H}_{28}$ & $\mathrm{~F} 3 \mathrm{H}_{1}$ & $\mathrm{~F} 3 \mathrm{H}_{28}$ \\
\hline $\begin{array}{l}\text { Organolepti } \\
\mathrm{s}\end{array}$ & $\begin{array}{l}\text { Warna hijau } \\
\text { tua, wangi } \\
\text { minyak } \\
\text { mawar, tidak } \\
\text { terjadi } \\
\text { pemisahan } \\
\text { fase, } \\
\text { membentuk } \\
\text { konsistensi } \\
\text { setengah } \\
\text { padat. }\end{array}$ & $\begin{array}{l}\text { Warna hijau } \\
\text { kehitaman, } \\
\text { wangi minyak } \\
\text { mawar, tidak } \\
\text { terjadi } \\
\text { pemisahan } \\
\text { fase, } \\
\text { membentuk } \\
\text { konsistensi } \\
\text { setengah } \\
\text { padat. }\end{array}$ & $\begin{array}{l}\text { Warna hijau } \\
\text { tua, wangi } \\
\text { minyak } \\
\text { mawar, tidak } \\
\text { terjadi } \\
\text { pemisahan } \\
\text { fase, } \\
\text { membentuk } \\
\text { konsistensi } \\
\text { setengah } \\
\text { padat. }\end{array}$ & $\begin{array}{l}\text { Warna hijau } \\
\text { kehitaman, } \\
\text { wangi } \\
\text { minyak } \\
\text { mawar, tidak } \\
\text { terjadi } \\
\text { pemisahan } \\
\text { fase, } \\
\text { membentuk } \\
\text { konsistensi } \\
\text { setengah } \\
\text { padat. }\end{array}$ & $\begin{array}{l}\text { Warna hijau } \\
\text { tua, wangi } \\
\text { minyak } \\
\text { mawar, tidak } \\
\text { terjadi } \\
\text { pemisahan } \\
\text { fase, } \\
\text { membentuk } \\
\text { konsistensi } \\
\text { setengah } \\
\text { padat. }\end{array}$ & $\begin{array}{l}\text { Warna hijau } \\
\text { kehitaman, } \\
\text { wangi minyak } \\
\text { mawar, tidak } \\
\text { terjadi } \\
\text { pemisahan } \\
\text { fase, } \\
\text { membentuk } \\
\text { konsistensi } \\
\text { setengah } \\
\text { padat }\end{array}$ \\
\hline $\begin{array}{l}\text { Homogen- } \\
\text { itas }\end{array}$ & Homogen & Homogen & Homogen & Homogen & Homogen & Homogen \\
\hline Tipe emulsi & $\mathrm{m} / \mathrm{a}$ & $\mathrm{m} / \mathrm{a}$ & $\mathrm{m} / \mathrm{a}$ & $\mathrm{m} / \mathrm{a}$ & $\mathrm{m} / \mathrm{a}$ & $\mathrm{m} / \mathrm{a}$ \\
\hline $\mathrm{pH}$ & $7,04 \pm 0,02$ & $6,91 \pm 0,02$ & $7,00 \pm 0,04$ & $6,82 \pm 0,02^{\mathrm{a}}$ & $6,90 \pm 0,02$ & $6,71 \pm 0,01$ \\
\hline Viskositas & $32666 \pm 288,68$ & $38833 \pm 4645,79$ & $35000 \pm 7365,46$ & $40000 \pm 1000$ & $74333 \pm 2081,67$ & $89000 \pm 1000^{\mathrm{a}}$ \\
\hline $\begin{array}{l}\text { Pemisahan } \\
\text { fase krim }\end{array}$ & $\begin{array}{l}\text { Tidak terjadi } \\
\text { pemisahan } \\
\text { fase dan } \\
\text { pecahnya } \\
\text { emulsi, } \\
\text { warna hijau } \\
\text { tua, wangi } \\
\text { minyak } \\
\text { mawar, tidak } \\
\text { terdapat } \\
\text { pertumbuha } \\
\text { n jamur. }\end{array}$ & $\begin{array}{l}\text { Tidak terjadi } \\
\text { pemisahan } \\
\text { fase dan } \\
\text { pecahnya } \\
\text { emulsi, warna } \\
\text { berubah } \\
\text { menjadi hijau } \\
\text { tua } \\
\text { kehitaman, } \\
\text { wangi minyak } \\
\text { mawar, tidak } \\
\text { terdapat } \\
\text { pertumbuhan } \\
\text { jamur. }\end{array}$ & $\begin{array}{l}\text { Tidak terjadi } \\
\text { pemisahan } \\
\text { fase dan } \\
\text { pecahnya } \\
\text { emulsi, warna } \\
\text { hijau tua, } \\
\text { wangi minyak } \\
\text { mawar, tidak } \\
\text { terdapat } \\
\text { pertumbuhan } \\
\text { jamur. }\end{array}$ & $\begin{array}{l}\text { Tidak terjadi } \\
\text { pemisahan } \\
\text { fase dan } \\
\text { pecahnya } \\
\text { emulsi, } \\
\text { warna } \\
\text { berubah } \\
\text { menjadi hijau } \\
\text { tua } \\
\text { kehitaman, } \\
\text { wangi } \\
\text { minyak } \\
\text { mawar, tidak } \\
\text { terdapat } \\
\text { pertumbuhan } \\
\text { jamur. }\end{array}$ & $\begin{array}{l}\text { Tidak terjadi } \\
\text { pemisahan } \\
\text { fase dan } \\
\text { pecahnya } \\
\text { emulsi, warna } \\
\text { hijau tua, } \\
\text { wangi minyak } \\
\text { mawar, tidak } \\
\text { terdapat } \\
\text { pertumbuhan } \\
\text { jamur. }\end{array}$ & $\begin{array}{l}\text { Tidak terjadi } \\
\text { pemisahan } \\
\text { fase dan } \\
\text { pecahnya } \\
\text { emulsi, warna } \\
\text { berubah } \\
\text { menjadi hijau } \\
\text { tua kehitaman, } \\
\text { wangi minyak } \\
\text { mawar, tidak } \\
\text { terdapat } \\
\text { pertumbuhan } \\
\text { jamur. }\end{array}$ \\
\hline $\begin{array}{l}\text { Aktivitas } \\
\text { antioksidan }\end{array}$ & $80,73 \pm 0,19$ & $80,43 \pm 0,20^{\mathrm{a}}$ & $83,05 \pm 0,23$ & $82,49 \pm 0,36^{a}$ & $83,51 \pm 0,19$ & $79,02 \pm 0,16^{a}$ \\
\hline
\end{tabular}

Keterangan : a = Menunjukkan adanya perbedaan yang signifikan, $\mathrm{F} 1 \mathrm{H}_{1}=$ Krim 1 hari ke-1, $\mathrm{F} 1 \mathrm{H}_{28}=$ Krim 1 hari ke-28, F2 $\mathrm{H}_{1}=$ Krim 2 hari ke-1, F2 $\mathrm{H}_{28}=$ Krim 2 hari ke-28, F3 $\mathrm{H}_{1}=$ Krim 3 hari ke-1, F3 $\mathrm{H}_{28}=$ Krim 3 hari ke-28.

\section{Pembahasan}

Pengujian aktivitas antioksidan terhadap ekstrak yaitu dengan metode peredaman DPPH yang merupakan radikal bebas atau zat pengoksidan yang stabil. Metode ini dapat digunakan untuk mengevaluasi aktivitas antioksidan pada ekstrak tanaman dan makanan. Keberadaan antioksidan akan menetralisasi radikal DPPH dengan menyumbangkan elektron pada DPPH menghasilkan perubahan warna dari ungu menjadi kuning (Jaya dkk, 2012). Penentuan aktivitas antioksidan dengan menggunakan metode peredaman DPPH dinyatakan dengan nilai peredaman DPPH dimana semakin besar nilai peredamannya maka semakin besar juga nilai aktivitas antioksidannya. Nilai $0 \%$ berarti larutan uji tidak mempunyai daya peredaman 
radikal bebas, sebaliknya nilai $100 \%$ berarti larutan uji mempunyai daya peredaman yang besar (Haryoto dkk, 2007).

Ekstrak daun kapas mengandung senyawa flavonoid, tanin,saponin, terpenoid dan fenolat. Senyawa-senyawa tersebut termasuk ke dalam golongan senyawa yang memiliki aktivitas sebagai antioksidan (Hernawan dan Setyawan, 2003; Pratiwi dkk, 2010; Sukmiwati, 2012; Lolaen dkk, 2013) yang dapat menangkap radikal bebas karena mengandung gugus hidroksil yang berfungsi sebagai reduktor sehingga dapat bertindak sebagai donor hidrogen terhadap radikal bebas (Silalahi, 2006).

Hasil pengamatan organoleptis terhadap formula krim F1, F2 dan F3 diperoleh hasil dari ketiga formula yaitu berwarna hijau tua, beraroma mawar, membentuk konsistensi setengah padat dan tidak mengalami pemisahan fase. Hasil pengamatan organoleptis pada hari ke-28 krim F1, F2, F3 tidak mengalami perubahan bau dan mengalami perubahan warna dari hijau tua menjadi hijau kehitaman. Adanya perubahan warna yang terjadi pada sediaan dipengaruhi oleh oksidasi dimana senyawa antioksidan mudah mengalami oksidasi sehingga menyebabkan perubahan warna selama penyimpanan (Lachman, 2008).Hasil pengujian homogenitas krim F1, F2, F3 menunjukkan ketiga krim memiliki homogenitas yang baik.

Hasil pengujian tipe krim F1, F2, F3 pada hari ke-1 dan hari ke-28 membentuk tipe krim minyak dalam air (m/a). Hal ini disebabkan karena volume fase terdispersi (fase minyak) yang digunakan dalam sediaan krim lebih kecil dari fase pendispersi (fase air), sehingga fase minyak akan terdispersi ke dalam fase air membentuk emulsi tipe minyak dalam air m/a (Lachman, 2008).

Perubahan $\mathrm{pH}$ yang terjadi pada sediaan sama dengan teori yang dikemukakan oleh Hadyanti (2008) yaitu perubahan pH disebabkan karena perubahan kimia zat aktif atau zat tambahan dalam sediaan, pengaruh wadah penyimpanan, pengaruh pembawa atau lingkungan, pengaruh $\mathrm{CO}_{2}$ karena $\mathrm{CO}_{2}$ bereaksi dengan fase air sehingga berubah menjadi asam.Hasil pengukuran $\mathrm{pH}$ yang diperoleh pada sediaan krim F1, F2, F3 tidak sesuai dengan $\mathrm{pH}$ kulit yang seharusnya 4,56,5 (Tranggono, 2007). Akan tetapi $\mathrm{pH}$ yang dimiliki ketiga sediaan tersebut masih berada pada kisaran $\mathrm{pH}$ netral $(\mathrm{pH}$ 7) sehingga tidak terlalu bersifat basa $(\mathrm{pH}>7)$. Menurut SNI (1996) "kulit yang memiliki pH 4,5 - 6,5 dapat beradaptasi dengan baik saat berinteraksi dengan bahan yang memiliki $\mathrm{pH}$ antara 4,58.0".

Pengujian viskositas dilakukan dengan kecepatan $2 \mathrm{rpm}$ dan menggunakan spindel No. 6. Sediaan krim formula F1 memiliki konsistensi yang lunak, krim formula F2 kental dan formula F3 mempunyai konsistensi yang sangat kental. Hal ini disebabkan karena konsentrasi emulgator yang berperan dalam pembentukan konsistensi krim dalam setiap formula berbeda. Hasil analisis statistik uji $t$ student terhadap perubahan viskositas pada hari ke-1 dan hari ke-28 menunjukkan bahwa data yang diperoleh pada sediaan krim F1 dan F2 tidak memiliki perbedaan yang signifikan sedangkan sediaan krim F3 mengalami perbedaan yang signifikan. Sedangkan pada uji ANOVA menunjukkan bahwa pada krim F1 dan F2 terdapat perbedaan yang signifikan pada krim F3. Hal ini disebabkan karena tingginya konsentrasi emulgator pada sediaan krim F3 sehingga menyebabkan konsistensi krim menjadi lebih meningkat selama penyimpanan.

Berdasarkan hasil analisis statistik uji $t$ studentdan ANOVA aktivitas antioksidan ketiga sediaan krim mengalami perbedaan yang signifikan pada hari ke-28. Hal ini disebabkan karena sediaan krim mengalami oksidasi selama penyimpanan.

Kesimpulan yang diperoleh dari penelitian ini adalahhasil penelitian menunjukkan bahwa variasi konsentrasi emulgator memenuhi mutu sediaan dengan beberapa parameter yakni organoleptik, homogenitas, tipe krim dan viskositas. $\mathrm{pH}$ sediaan krim tidak memenuhi syarat yang ditentukan yakni 4,5-6, namun masih berada dalam kisaran $\mathrm{pH}$ netral $(\mathrm{pH} \pm 7)$. Formula yang memenuhi parameter uji kestabilan fisik sediaan adalah krim F1 yang mengandung ekstrak daun kapas dengan perbandingan emulgator asam stearat dan trietanolamin (8\%:2\%).Aktivitas antioksidan ke tiga formula krim ekstrak daun kapas memiliki aktivitas antioksidan yang baik dengan persen peredaman antara $79,02 \%$ sampai $82,49 \%$ hingga 28 hari penyimpanan. 
DAFTAR PUSTAKA

Anief, M.(2008). Ilmu Meracik Obat Teori dan Praktik.Yogyakarta. Gadjah Mada University Press.

Budiman, M.H.(2008). UjiStabilitas Fisik dan Aktivitas Antioksidan Sediaan Krim yang Mengandung Ekstrak Kering Tomat (Solanum licopersicum L.) (Skripsi). Universitas Indonesia. Depok.

Hadyanti.(2008).Pengaruh Tretinoin Terhadap Penetrasi Kafein dan Aminofilin Sebagai Antiselulit Dalam Sediaan, Krim, Gel, dan Salep Secara In Vitro. Universitas Indonesia. Depok.

Hernawan, U. E. \& Setyawan, A.D. (2003).Review : Ellagitanin; Biosintesis, Isolasi, dan Aktivitas Biologi, Jurnal Biofarmasi 1(1).

Indrayani, I.\& Sumartini, S. (2012). Pengaruh Kerapatan Bulu Daun Dan Kelenjar Gosipol Terhadap Infestasi Hama Pengisap Daun Amrasca Biguttula Ishida dan Penggerek Buah Helicoverpa Armigera Hubner Pada Kapas. Jurnal Vol 18(3).

Ketaren, S. (2008). Pengantar Teknologi Minyak dan Lemak Pangan. Universitas Indonesia (UI) Press.Jakarta.

Kosasih, E, N., Tony, S. \& Hendro, H. (2006). Peran Antioksidan pada Lanjut Usia. Pusat Kajian Nasional Masalah Lanjut Usia. Jakarta.

Kumar, S.P., Singh S.S., Singh Naruka, P., Mayur, P. (2011). In-vitro Antioxidant Activity of Gossypium herbaceum L. International Research Journal of Pharmacy, 2( 7).

Lachman, L. (2008). Teori dan Praktek Farmasi Industri II. Penerbit UI-Press. Jakarta.

Lolaen, L. A. C. H., Fatimawali, Citraningtyas, G. (2013). Uji Aktivitas Antioksidan Kandungan Fitokimia Jus Buah Gandaria (Bouea macrophylla Griffith). Pharmacon Jurnal Ilmiah Farmasi Unsrat, 2(02).
Maulida, D., \& Zulkarnaen, N. (2010). Ekstraksi Antioksidan (Likopen) dari Buah Tomat Dengan Menggunakan Solven Campuran, $n$-Heksan, Aseton dan Etanol, (Skripsi). Universitas Diponegoro. Semarang.

Pratiwi, P., Suzery, M., Cahyono, B.C (2010). Total Fenolat dan Flavonoid dari Ekstrak dan Fraksi Daun Kumis Kucing (Orthosiphon stamineus B.) Jawa Tengah Serta Aktivitas Antioksidannya. Jurnal Sains dan Matematika (JSM), 18(4).

Silalahi, J. (2006). Makanan Fungsional. Penerbit Kanisius. Yogyakarta.

Sinaga, I. (2009). Skrining Fitokimia dan Uji Aktivitas Antioksidan dari Ekstrak Etanol Buah Terong Belanda (Solanum betaceum Cav.) (Skripsi). Universitas Sumatera Utara. Medan.

Siswati, N.D., Juni, Junaini. (2010). Pemanfaatan Antioksidan Alami Flavonol Untuk Mencegah Proses Ketengikan Minyak Kelapa. Jurnal Teknologi Pangan, 4(1).

SNI 16-4399-1996.(1996). Sediaan Tabir Surya. Badan Standarisasi Nasional. Jakarta.

Sukmiwati, M. (2012). Uji Aktivitas Antioksidan Pada 16 Spesies Teripang Yang Ditemukan Pada Perairan Natuna Kepulauan Riau, Prosiding Semirata BKS PTN-B MIPA. Universitas Riau. Riau.

Sutikno, I. (2000). Tanaman Kapas Kaitannya Dengan Gosipol. Balai Penelitian Ternak, Wartazoa, 10(1).

Syamsuni. (2006). Farmasetika Dasar dan Hitungan Farmasi. Penerbit Buku Kedokteran EGC, Jakarta. 
Hasniar et al./Galenika Journal of Pharmacy

Tranggono, I.R. \& Latifah, F. (2007). Buku Pegangan Ilmu Pengetahuan Kosmetik. PT. Gramedia Pustaka Utama. Jakarta.
Winarsi, H. (2007). Antioksidan Alami dan Radikal Bebas. Penerbit Kanisius. Yogyakarta. 